\title{
ESTUDIOS
}

\section{Los dos Asturias}

La fama de Miguel Angel Asturias, desde la publicación de El Señor Presidente, en 1946, hasta el Premio Nóbel de Literatura 1967, ha sufrido curiosas alternativas que convendría examinar, así sea brevemente. Un primer período de su éxito corresponde a la década 1946/1956. Entre esas dos fechas, Asturias no sólo da a conocer su primer novela importante sino que, también, produce una serie de relatos y hasta una novela-río que cuentan entre lo más destacado que se escribe entonces en América Latina. La publicación sucesiva de El Señor Presidente (1946), de Hombres de maíz (1949), de los dos primeros volúmenes de una tetralogía aún inconclusa, Viento fuerte (1950) y El Papa Verde (1954), más una serie de relatos, Weekend en Guatemala (1956), permiten fijar una imagen que es, para muchos, la única viable. Es la imagen de un poderoso narrador, que hunde sus raíces en la tradición cultural y mitológica de su patria, Guatemala, y a la vez aprovecha tradiciones más recientes, como la del superrealismo francés, para presentar en una serie de libros el trágico destino de una tierra saqueada por el imperialismo económico. En esa década, Asturias impresiona como un narrador a la vez exquisito y popular, un escritor que sabe mezclar el impulso poético con la denuncia política y social. Sus libros aparecen superpuestos simultáneamente a las dos corrientes que entonces se disputan el campo narrativo latinoamericano. Si por sus temas y por su actitud comprometida, Asturias está del lado de los novelistas de la tierra y la protesta, por su preocupación lingüistica y por su temperamento poético, Asturins no está lejos de sus coetáneos más importantes: de Borges, de Leopoldo Marechal, de Alejo Carpentier, de Agustín Yáñez.

Una segunda etapa de su obra narrativa puede discernirse a partir de 1956. Aunque continúa con un tercer volumen su tetralogía, Los ojos de 
los enterrados (1960), y se prolonga con algunos títulos más, El albajadito (1961), Mulata de tal (1963), El espejo de Lida Sal (1967), es evidente que esta segunda década es mucho menos importante, tanto del punto de vista de la producción narrativa de Asturias como del punto de vista del contexto latinoamericano en que aparece inscrita. Si la obra de la primera década sobresale entre la publicada por sus coetáneos, no pasa lo mismo con la de la segunda época. Es éste un periodo en que no sólo Onetti, Sábato, Cortázar, Lezama Lima, Guimarâes Rosa y Jorga Amado producen su mejor obra, sino que asoman dos y hasta tres generaciones de narradores más jóvenes que habrán de transformar radicalmente la estimativa literaria. En ese contexto, los libros que publica Asturias parccen en el mejor de los casos (El albajadito, fragmentos de Mulata) reiteraciones de lo que él ya había hecho bien e incluso mejor en la década anterior. En el peor de los casos, como sucede con Los ojos ie los enterrddos, Asturias sólo revela un apego a fórmulas superadas y que él mismo había logrado superar.

Todo esto, hasta cierto punto, cs bien sabido aunque no todos los críticos latinoamericanos lo suelan plantear con nitidez. Lo que no es tan sabido, cs qué encubre esta situación doble o ambigua de la obra narrativa de Asturias. Habría que empezar por preguntarse, entonces: ¿Cuál es la paradoja que encierra la obra de este indudablemente gran escritor? Las notas que siguen no pretenden agotar el tema. Apenas buscan plantedito en correctos términos literarios.

\section{LOS NIVELES DE UNA ESCRITURA}

Conviene empezar por el principio. Aunque la primera obra narrativa importante de Asturias no es El Señor Presidente (su creación en este género comienza con las Leyendas de Guatemala, de 1930), es evidente que se puede iniciar el examen con aquella novela ya que lo mejor de las Leyendas resultará incorporado a libros posteriores de Asturias, y en particular a Hombres de maiz y Mulata de $t a l$. No en balde, El Señor Presidente es el libro que enfoca la atención del lector latinoamericano sobre este guatemalteco de 47 años (nació en 1899), que vivía en la Argentina, desterrado de su patria. La novedad de El Señor Presidente en el contexto de 1946 fue, sobre todo, la novedad de su estilo. Se habian escrito ya muchas novelas para denunciar el abuso de autoridad, la tiranía económica, el atropello social, que esconden la mayor parte de los regímenes "democráticos" de América Latina. Pero ninguna novela había sabido explotar con tanta fuerza e imaginación lingüistica una situación 
tan rica en posibilidades. Asturias ha dicho que empieza a escribir su novela en 1922 y que la concluye en 1932. No hay por qué dudar de estas fechas tempranas. Son las fechas en que están despiertas en él aún las memorias de su infancia y adolescencia, vividas en Guatemala bajo Ja tiranía de Estrada Cabrera. Son las fechas en que Asturias reside en París, ayudando a su profcsor Georges Raynaud a traducir el Popol $V u h$ y colaborando con otros jóvenes estudiantes (como el peruano Víctor Raúl Haya de la Torre o el uruguayo Carlos Quijano) en la fundación de un centro latinoamericano.

Esas fechas son, también, las fechas en que se difunde en todo el mundo de habla española Tirano Banderas (1926), de Valle Inclán, el antecedente obligado de El Señor Presidente, ya que en la esperpéntica novela del narrador gallego encuentra Asturias el estilo y enfoque que permitirá a su novela ese doble golpe maestro de poesía y política. No quiero decir con esto que Asturias lo ha tomado todo de Valle Inclán. Por el contrario, un examen algo detenido de ambas obras podría demostrar que las semejanzas son más bien superficiales. En Valle Inclán todo es más literario. En Asturias, la exasperación literaria es máscara de una exasperación emocional que tiene cuño más apasionado y romántico. En cierto sentido, la obra de Valle Inclán está más cerca de otro antecedente de este tipo de novelas, de la famosa Nostromo, de Joseph Conrad. Pero lo que me interesa apuntar ahora es que, asi como Asturias descubre en el Popol $V u b$ y en el superrealismo francés, una mina para su creación poética, en Tirano Banderas descubre un procedimiento para exasperar aún más la denuncia de un régimen que odia.

El mayor mérito de El Señor Presidente está pues en su pasión, en la fuerza con que arrastra al lector en la primera lectura y que se pone en evidencia, sobre todo, en los primeros capítulos, a partir de la brillante descripción del Portal del Señor y del crimen que allí comete el idiota Pelele. Pasado ese momento, aunque el libro sigue interesando al lector como retrato exasperado de un mundo en total proceso de descomposición, la novela revela (a una segunda lectura) importantes debilidades de estructura. Para decirlo brevemente: el poder descriptivo, la felicidad del lenguaje, el sistema de brillantes metáforas, no se sostiene (como en Tirano Banderas) de la primera a la última página. Asturias debe rellenar los huecos de su composición con pasajes chatos, la línea melodramática del argumento cruje y rechina bajo el peso de toda suerte de clisés narrativos y verbales, un folletín se desliza misteriosamente hasta instalarse en el centro de la novela.

El Señor Presidente falla por ese centro. Allí no está la figura, ad- 
mirablemente trazada, del personaje titular, sino la de su favorito, Miguel Cara de Angel, personificación un poco obvia de la "beauté du diable". Al ir desarrollando la historia de Cara de Angel, su complicidad con el dictador para comprometer y hasta asesinar a uno de los rivales políticos de éste; al mostrar a Cara de Angel como venal e inescrupuloso y luego hacerle dar una vuelta completa para presentarlo enamorado de la hija de su víctima y dispuesto a enfrentar al dictador, Asturias está modificando profundamente la visión inicial del libro. Ese salto h:cia la novela sentimental no se realiza sin grandes pérdidas. La visión a la vez feroz y brillante de la primera parte se hunde en el melodrama. Aunque al final se rescata parte de la ferocidad, el sentimentalismo acaba por distruir el centro emocional del libro.

Estilísticamente el defecto es muy evidente en las variaciones enormes que sufre la novela a lo largo de su curso. Capítulos esperpénticos como los iniciales son reemplazados por páginas y páginas de narración realista. Algunos críticos, entusiasmados por sus pasajes más purpúreos, han llegado a afirmar que "el autor omnisciente lo ha poetizado todo". Esta afirmación contiene un delicado error. Una lectura sobria y atenta de la novela demuestra que lejos de poetizarlo todo, Asturias ha dejado grandes fragmentos de prosa más o menos realista sobresaliendo, como indigesta masa, en un estilo por lo general inventivo y poético. ¿Cómo explicar estos dos niveles de la escritura de El Señor Presidente?

Adelanto una hipótesis que tal vez pueda confirmarse con el examen de otra obra crucial, la serie que inaugura Viento fusre. Hay en Asturias un narrador convencional, de buen oficio realista, de escritura fácil y fluida, que se manifiesta sobre todo en la textura básica, el tejido conjuntivo, de sus libros. Pero hay también en él un foeta, un narrador mágico, que ambiciona tocar otras dimensiones de la realidad. Ese otro Asturias es el que se encabrita contra la narración realista y borda sobre ella, o en sus intersticios, los fragmentos de descripción, los trenos melódicos, la imaginería de origen a la vez maya y superrealista. En El Señor Presidente las dos escrituras alternan y hasta se superponen como en un palimpsesto. Hasta se podría sostener que Asturias empezó tal vez su novela en una vena de escritura poética y después la fue lastrando de realismo, o (viceversa) que la empezó dentro de las convenciones del realismo y la fue reescribiendo hacia una mayor tensión imaginativa. Sca cual fuere el proceso ( $y$ éste es asunto que interesará elucidar a futuros investigadores de su obra), es claro que El Señor Presidente no puede ser leído - como Nostromo o Tirano Banderas-, como una obra unitaria, de estractura literaria válida y escritura uniforme. Es un híbrido. 
UN LIBRO CAPITAL

Muy distinto es el caso de la serie de relatos que se titula Hombres de maíz. Aquí Asturias ha conseguido precisamente lo que se le escapó en $E l$ Señor Presidente. Los sucesivos capitulos que van presentado a estos seres del maíz, resuelven sus tensiones narrativas por un mismo procedimiento: mezclar el relato realista (que refiere las luchas entre los indios que siembran el maíz para alimentarse, y los criollos que lo hacen sólo para ganar dinero) con los procedimientos poéticos de la narración maya. En este gran libro no hay límites entre lo real y lo sobrenatural, sus personajes viven simultáneamente el ahora y el ayer $\mathrm{y}$ también el futuro, son ellos mismos y sus antepasados, son ellos y sus animales totémicos, atraviesan las barreras del tiempo y del espacio, son convocados mágicamente, son médiums. La importancia de este libro para la narrativa latinoamericana no puede ser bastante encarecida. En un momento en que todavia triunfaba en América Latina la voz de los narradores reaIistas, y en que un intento como el de Borges en la Argentina por aclimatar la literatura fantástica era visto con irrisión por respetados críticos de entonces, Asturias salta la barrera que separaba artificialmente estos dos campos y crea un libro en que el telurismo se duplica de magia, en que la protesta social se hace también sobrenatural. La importancia de esta revolución se habría de ver años más tarde cuando Rulfo publica su Pedro Páramo (1955), Guimarâes Rosa su Grande Sertâo: Veredas (1956), y Gabriel García Márquez sus Cien años de soledad (1967).

Pero dentro de la obra de Asturias, Hombres de maiz marca no sólo an punto culminante (su obra maestra, a mi juicio) sino un momento de perfección que, ni antes ni después, el inquieto narrador guatemalteco rolvería a alcanzar. El intento de Mulata de tal, hasta cierto punto equiparable al de Hombres de maiz, no se sostiene por un defecto de concepción. En vez de consistir, como esta obra, en una serie independiente de relatos, vinculados por la misma situación básica y por el préstamo de personajes, Mulata de tal se convierte en una serie infinita, y a la postre tediosa, de variaciones sobre motivos indigenas. La fórmula aqui no funciona, o funciona sólo ocasionalmente.

\section{LAS BUENAS RAZONES POLÍTICAS}

Desde otro punto de vista, Hombres de maiz marca el fin de una etapa y el comienzo de otra en la evolución narrativa de Asturias. El éxito de este libro y de El Señor Presidente, impulsa a Asturias a intentar 
un esfuerzo narrativo mayor: la serie sobre la explotación bananera norteamericana en Guatemala. Iniciada con Viento fuerte, continuada con El Papa Verde y Los ojos de los enterrados, la serie no ha concluido aun cuando escribo estas líneas. Por lo que se ha publicado es fácil, sin embargo, deducir las grandes líneas de la estructura general. Esta novela-río expande la visión de Hombres de maiz mostrando la otra cara del conflicto social, político $\mathrm{y}$ económico que en aquellos relatos era casi invisible. Ahora no sólo se ve la explotación desde el ángulo de los explotados. También se la muestra desde el ánguio de los explotadores.

En buena medida, y como ha observado uno de sus críticos, Alexander Coleman, Asturias establece un claro contraste entre el mundo de las victimas y el de los victimarios. En tanto que los indigenas son presentados como seres pasivos que casi nunca tienen éxito en su tebelión y que carecen de verdadera iniciativa, los explotadores aparecen como personajes complejos, llenos de buenas y malas intenciones pero en definitiva malos. Se reproduce aquí el esquema típico de El Señor Presidente: el villano es también el héroe. Si en aquella novela, Cara de Angel terninaba redimido por amor, en éstas, es el gringo, el explotador, el imperialista, el que intentará redimir (a su manera) a los indígenas, haciéndolos incluso propietarios de las bananeras que le pertenecen, lo que no resuelve el problema económico. Por otra parte, hasta los villanos más siniestros aparecen en esta moderna moralidad como individuos atractivos y seductores, incurables y diligentes Donjuanes.

Otra vez "la beauté da diable". Lo que nos lleva a la esencia de la visión de Asturias. Es una visión maniqueísta. Para él no hay duda de que el imperialismo económico de los Estados Unidos es el Diablo, con cola y todo. En tanto que Dios está del lado de los indígenas. Lástima que esta visión maniqueista no haga justicia a la realidad tan compleja de la América Latina de hoy. Porque aunque sea posible compartir su denuncia del imperialismo y reconocer la verdad de muchas de sus comprobaciones narrativas, es casi imposible aceptar que la realidad total pueda ser dividida, tan teológicamente, en zonas puras. De ahí que la impresión dominante que producen estas novelas es la de su irrealidad. Son moralidades a la manera medieval, cuentos para adormecer el espíritu crítico, simplificaciones para estimular la protesta verbal. Pertenecen a la misma línea de pensamiento que en Estados Unidos generó la literatura de Upton Sinclair y en Alemania las sátiras de Bertolt Brecht. Como agitación, como propaganda, como incitación al escándalo, tal vez sean eficaces. Como retrato de una realidad tienen la dimensión de una fábula de Calleja.

Esto es lamentable porque en su centro mismo la denuncia de Astu- 
rias tiene mucha justificación. $Y$ los acontecimientos que ocurrieron en Guatemala en la época en que se émpezó a publicar esta serie de novelas dieron razón política a Asturias. Pero las buenas razones políticas hacen mala literatura. Volver a leer hoy esas novelas es sufrir por sus simplificaciones, padecer por el melodrama de sus situaciones, entristecerse por el predominio de una escritura chata, borrosa, gris, que está apenas aliviada, aquí y allá, por estallidos súbitos, fugaces, del talento literario que fue capaz de escribir Hombres de maiz. El otro Asturias, el periodista de combate, domina este ciclo. Con Weekend en Guatemala las cosas no mejoran mucho aunque hay algún relato ("La Galla", por ejemplo) que tiene brío y calidades. Pero Asturias parece más empeñado entonces en ser cronista de una época que en ser su recreador.

\section{UN EVIDENTE DIVORCIO}

En el contexto de la narrativa que empieza a publicarse en América Latina precisamente hacia 1960, cuando aparecen Los ojos de los enterrados, la escritura de esta serie resulta aún más anacrónica. Si Cortázar quiere mostrar el desarraigo argentino, o Fuentes la alienación mexicana, o Vargas Llosa el fascismo de cierta mentalidad castrense de su patria, o García Márquez las raíces de la violencia colombiana, y Cabrera Infante el lenguaje de una generación perdida de La Habana pre-revolucionaria; si alguno de estos grandes narradores quiere hacer participar al lector en una realidad muy honda y entrañable, lo último que hace es lo que hace Asturias. En vez del discurso, del panfleto, del maniqueísmo, Cortázar y Fuentes, Vargas Llosa y García Márquez, Cabrera Infante ofrecen dimensiones complejas de una realidad que tiene muchas faces, muchos tonos, muchos infiernos, y algunos cielos. Por eso, a medida que Asturias iba publicando los volúmenes de su novela-río, el divorcio entre su óptica y la de los mejores escritores latinoamericanos de hoy se hacía más evidente.

La paradoja que encierra esta situación es doble. Por un lado, Asturias no sólo se separaba de los más jóvenes; también se separaba de sus propios orígenes narrativos, de esas Leyendas de Guatemala que lo lanzan en el París del año 30, de lo mejor de El Señor Presidente, del logro de Hombres de maíz. Precisamente aquellas obras suyas que, como ha apuntado acertadamente Carlos Fuentes, inauguran en cierto sentido una nueva dimensión en el tratamiento del telurismo latinoamericano. Peto hay otra cara de la misma paradoja: a medida que Asturias completa su novela-rio, su propia posición política oscila hacia el centro. En 1966 acepta ser 
Embajador de Guatemala en París y de esa manera une su destino político al de grupos que él había combatido. La izquierda latinoamericana no ha perdonado a Asturias esta actitud, especialmente en momentos en que nuevos brotes de guerrilla asolaban su patria.

Por eso, el Premio Nóbel que viene a consagrar en 1967 su obra llega con casi veinte años de retraso. Otorgado en 1949, cuando Asturias habia publicado sus tres libros más importantes, habría sido unánimemente aplaudido. En 1967 es un anacronismo y más que premiar a Asturias sirve para demostrar que hasta la Academia Sueca se da hoy por enterada de la existencia de una literatura narrativa cuya importancia es cada día más grande en el mundo actual: la latinoamericana. Para Asturias, el Premio es una satisfacción y una satisfacción (insisto) que se merecia desde hacía por lo menos veinte años. Pero la obra que viene a consagrar el Premio está, en buena medida, superada por las nuevas generaciones $y$, lo que es más increíble, por la propia obra del Asturias de su primera madurez. El Premio cae sobre un Asturias que no es el más representativo. Como creo que ha hecho abundantemente claro este artículo, el que merecía el premio es el otro Asturias.

Yale University, 1969

EMIR RODRíGuEZ MONEGAL 